\title{
Correlation between low serum vitamin D levels and Gestational Diabetes Mellitus among pregnant women in the rural area attending tertiary care center
}

\author{
Kiranmai G. ${ }^{\mathbf{1}}$, Indira B. ${ }^{2 *}$ \\ DOI: https://doi.org/10.17511/joog.2020.i05.01
}

${ }^{1}$ Kiranmai G., Associate Professor, Maharajahs Institute of Medical Sciences, Vizianagaram, Andhra Pradesh, India.

2* Bommi Indira, Assistant Professor, Maharajahs Institute of Medical Sciences, Vizianagaram, Andhra Pradesh, India.

Background: Diabetes mellitus with the first onset in pregnancy is known as gestational diabetes mellitus (GDM) which is a common complication of pregnancy. Maternal vitamin D status has been associated with gestational diabetes mellitus (GDM) but the evidence is inconsistent. During pregnancy, this deficiency is even more critical. It appears that vitamin $D$ insufficiency during pregnancy may be associated with maternal hazards. Methods: This study included 200 pregnant women. 100 women already diagnosed with GDM were taken as cases and 100 normal pregnant women were taken as control. All the patients included were subjected to detailed history taking. BMI matched in cases and controls. Blood samples were taken from both cases and control ant sent for Vitamin-D level, HbA1c, fasting blood glucose, and $2 \mathrm{hrs}$ postprandial glucose test. Results: Overall $78 \%$ of Indian women are vitamin D deficient in the present study. The mean maternal serum vitamin $D$ levels were $9.25 \pm 6.07$ in GDM cases and in the controls the mean is $18.11 \pm 7.86$. The difference was statistically significant reflecting that the mean serum vitamin $D$ was decreased in women with GDM. Vitamin D levels correlated significantly with the fasting blood glucose, the fasting serum insulin, and the HbA1c levels, the P-value in all these correlations were $<0.0001$. Conclusions: Low maternal serum vitamin d levels were associated with gestational diabetes mellitus. There is a statistically significant negative correlation between glycemic control and vitamin $\mathrm{D}$ levels in serum in the whole study population.

Keywords: Vitamin D levels, Gestational diabetes mellitus, Pregnancy, Fasting blood glucose, HbA1c

Corresponding Author

Bommi Indira, Assistant Professor, Maharajahs Institute of Medical Sciences, Vizianagaram, Andhra Pradesh, India.

Email: kiranmaigottapu@yahoo.com
How to Cite this Article

To Browse

Kiranmai G, Indira B. Correlation between low serum

vitamin D levels and Gestational Diabetes Mellitus among pregnant women in the rural area attending tertiary care center. Obs Gyne Review J Obstet Gynecol. 2020;6(5):102-107.

Available From

https://obstetrics.medresearch.in/index.php/joog/art

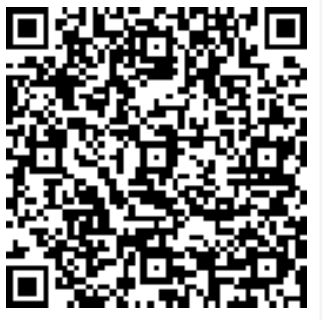
icle/view/120

\begin{tabular}{|c|c|c|c|c|c|}
\hline \multicolumn{2}{|c|}{$\begin{array}{c}\text { Manuscript Received } \\
2020-10-06\end{array}$} & $\begin{array}{c}\text { Review Round } 1 \\
2020-10-16\end{array}$ & $\begin{array}{c}\text { Review Round } 2 \\
2020-10-22\end{array}$ & Review Round 3 & $\begin{array}{c}\text { Accepted } \\
2020-10-29\end{array}$ \\
\hline & $\begin{array}{l}\text { Conflict of Interest } \\
\text { No }\end{array}$ & $\begin{array}{l}\text { Funding } \\
\mathrm{Nil}\end{array}$ & $\begin{array}{c}\text { Ethical Approval } \\
\text { Yes }\end{array}$ & $\begin{array}{c}\text { Plagiarism X-checker } \\
\qquad 8 \%\end{array}$ & Note \\
\hline 0 & $\begin{array}{l}\text { (C) } 2020 \text { by } \mathrm{k} \\
\text { AcCESS }\end{array}$ & $\begin{array}{l}\mathrm{mmi} \text { Indira and Pub } \\
\text { article licensed und } \\
\text { https://creativeco }\end{array}$ & $\begin{array}{l}\text { ddharth Health Resea } \\
\text { Commons Attributic } \\
\text { licenses/by/4.0/ unp }\end{array}$ & $\begin{array}{l}\text { Welfare Society. This is } \\
\text { onal License } \\
\text {.0]. }\end{array}$ & \\
\hline
\end{tabular}




\section{Introduction}

Gestational diabetes mellitus (GDM) is defined as carbohydrate intolerance of variable severity with onset or first recognition during pregnancy [1]. Gestational diabetes mellitus (GDM) is one of the most common medical complications of pregnancy. The disease has important health implications for mother and child.

Early diagnosis and treatment of GDM can reduce adverse pregnancy outcomes, including stillbirth, neonatal macrosomia, neonatal hypoglycemia, birth trauma, and neonatal respiratory distress syndrome as well as decrease the risk of preeclampsia in the mother [2]. Vitamin D deficiency is closely associated with Gestational Diabetes Mellitus (GDM). Vitamin D induces insulin receptor expression through Vitamin D receptor (VDR), enhancing insulin-dependent glucose transport. Vitamin $D$ is also a potential immunosuppressant, which down-regulates the expression of proinflammation markers, such as TNF-a and IL-2, among pregnant women with GDM [3].

In recent years, vitamin $D$ deficiency has been increasingly recognized as one potential contributor [4]. While epidemiologic studies have shown a fairly consistent link between vitamin $D$ deficiency and a higher risk of type 2 diabetes $[5,6]$, and obesity is strongly associated with both $\operatorname{GDM}[7,8]$ and vitamin $D$ deficiency $[9,10,11]$, it remains unclear whether vitamin D deficiency contributes to a mother's risk of developing GDM. Compelling evidence suggests a role of vitamin D deficiency in the pathogenesis of insulin resistance and insulin secretion derangements.

The coexistence of insulin resistance and vitamin $D$ deficiency has generated several hypotheses as worsening insulin resistance [12]. Immense interest persists in vitamin $D$ and its potential effects on several pregnancy outcomes including fetal growth, hypertensive disorders, and gestational diabetes mellitus (GDM) [13].

Two factors make vitamin $D$ intriguing to perinatal investigators studying GDM. First, vitamin D has been shown to improve pancreatic exocrine function and insulin sensitivity in animal models. Second, vitamin D status, like most micronutrients, is easily modified by dietary supplementation [13].

The major source of vitamin $D$ is skin after sunlight exposure.
Cutaneous vitamin $D$ synthesis is modulated by several factors including skin pigmentation, clothing, melanin concentration, latitude, climate type, and season [14]. Vitamin D, either produced in the skin de Novo from cholesterol (cholecalciferol) or ingested from the diet as a precursor (cholecalciferol and ergocalciferol), undergoes hydroxylation to 25-hydroxyvitamin $D(25(\mathrm{OH}) \mathrm{D})$ in the liver.

Circulating plasma concentration of $25(\mathrm{OH}) \mathrm{D}$ is considered the most reliable indicator of an individual's vitamin D status. $25(\mathrm{OH}) \mathrm{D}$ is further hydroxylated to the active 1,25-dihydroxyvitamin D $(1,25(\mathrm{OH}) 2 \mathrm{D})$ almost exclusively in the kidney upon regulation by parathormone [15].

Several studies have consistently shown that $1,25(\mathrm{OH}) 2 \mathrm{D}$ concentration increases progressively during gestation being twice as high in late pregnancy as in postpartum or in nonpregnant controls $[15,16]$. The active form $1,25(\mathrm{OH}) 2 \mathrm{D}$ is also produced by the placenta during pregnancy [17] with possible autocrine or paracrine function [18].

\section{Aim of the study}

$\S$ To determine the relationship between low maternal serum vitamin D levels and gestational diabetes mellitus (GDM).

\section{Methods}

Study setting: Department. of Obstetrics and Gynaecology, Maharajah's Institute of Medical Sciences, Vizianagaram.

Type and duration of study: This study was a hospital-based case-control observational study conducted in Dept. of Obstetrics and Gynaecology from November 2018 to January 2019.

Sample size: 200 pregnant women, in the third trimester, attending the antenatal care clinic within the target age group of $20-40$ years.

Exclusion criteria: $\mathrm{H} / \mathrm{O}$ type 1 or 2 diabetes mellitus antedating pregnancy, medical disorders (HTN, Cardiac diseases, etc.), and medical complications related to pregnancy.

Inclusion criteria: Pregnant women in their 3rd trimester with an established diagnosis of GDM as per DIPSI guidelines and pregnant women with normal blood sugar attending ANC. 
The study was conducted after the Institutional Ethics Committee approval.

Data collection: 100 pregnant women in their 3rd trimester with an established diagnosis of GDM as per DIPSI guidelines and randomly selected 100 pregnant women with normal blood sugar attending ANC were enrolled and taken as cases (Group A) and controls(Group B) respectively after written and informed consent.

They were subjected to detailed history taking with special focus on maternal age, parity, gestational age at diagnosis of gestational diabetes, previous history or family history of diabetes, history of gestational diabetes in previous pregnancies.

Data concerning insulin regimens, insulin types, and doses were also noted. Complete general physical examination, systemic examination, and obstetric examination. Body Mass Index (BMI) was calculated for all subjects and matched in cases and controls. A blood sample was collected from both cases and control and sent for laboratory investigations. Assessment of serum $25(\mathrm{OH})$ Vitamin $D$ was done by using the CLIA method.

Result of both groups was compared to evaluate association in maternal plasma 25- Hydroxyvitamin $D$ level and GDM. Reference value of maternal plasma 25-Hydroxyvitamin-D level- Deficiency $<20 \mathrm{ng} / \mathrm{ml}$; Insufficiency 20-30 $\mathrm{ng} / \mathrm{ml}$; Sufficiency $>30 \mathrm{ng} / \mathrm{ml}$. Glycosylated hemoglobin is a blood glucose control marker in diabetic patients. HbA1c was measured by chemiluminescence to assess glycemic control. Data collection and statistical analysis were done.

Statistical Analysis: Statistical analysis was performed by the SPSS program for Windows, version 17.0 (SPSS, Chicago, Illinois). Continuous variables are presented as mean \pm SD, and categorical variables are presented as absolute numbers and percentages. Data were checked for normality before statistical analysis. For all statistical tests, a p-value of less than 0.05 was taken to indicate a significant difference.

\section{Results}

200 women in their third trimester were enrolled in the study. 100 women with already diagnosed GDM were taken as cases and 100 normal pregnant women as cases. The mean age of cases and controls was $26.42 \pm 6.35$ and $25.84 \pm 6.23$. It was not statistically significant.
In the current study out of 200 subjects were 21 [10.5\%] vegetarian and 179 [89.5\%] subjects were non-vegetarian. Group A (Cases) had low physical activity in sun. Past h/o GDM is an important risk factor for GDM. No correlation was found with a family history of Diabetes mellitus. Calcium intake and periconceptional multivitamin intake had no association with GDM.

In the current study, vitamin deficiency was seen in $78 \%$ of the study population out of 200 subjects. The mean level of Vitamin D is $9.25 \pm 6.07$ in GDM cases and the controls the mean is $18.11 \pm 7.86$. Thus, a low level of Vitamin $D$ was seen in patients with GDM.

A significant inverse correlation was found between the HbA1C levels and Vitamin D levels ( $P$-value $<0.05$ ), where the higher the Levels of Vitamin $D$, the lower the HbA1c levels indicating good glycemic control in women with gestational diabetes. An inverse association was also found with the fasting blood sugar levels which were statistically significant.

Table-1: Clinical and biochemical, demographic data of the groups.

\begin{tabular}{|l|l|l|}
\hline \multicolumn{1}{|c|}{ Variables } & \multicolumn{1}{|c|}{$\begin{array}{c}\text { Group-A (n=100, } \\
\text { cases) }\end{array}$} & \multicolumn{1}{|c|}{$\begin{array}{c}\text { Group-B ( } \mathbf{n = 1 0 0 ,} \\
\text { controls) }\end{array}$} \\
\hline Maternal age & $26.42 \pm 6.35$ & $25.84 \pm 6.23$ \\
\hline H/O GDM & $8.00 \%$ & $0.00 \%$ \\
\hline Family h/o type 2DM & $9.00 \%$ & $6.00 \%$ \\
\hline Calcium intake & $63.00 \%$ & $71.00 \%$ \\
\hline Periconceptional & $26.00 \%$ & $31.00 \%$ \\
\hline multivitamin & & $32.00 \%$ \\
\hline Physical activity in the sun & $8.00 \%$ & \\
\hline >3hrs) & & $80.12 \pm 4.84$ \\
\hline Fasting blood sugar & $96.24 \pm 7.22$ & $5.2 \pm 0.31$ \\
\hline HbA1c & $6.81 \pm 1.18$ & $18.11 \pm 7.86$ \\
\hline Vitamin D & $9.25 \pm 6.07$ & \\
\hline
\end{tabular}

\section{Discussion}

Vitamin D seems to have several extraskeletal functions including regulation of glucose metabolism through influencing insulin sensitivity, although the mechanisms are not fully understood. The pancreatic $\beta$ cells express both vitamin $D$ receptor and enzyme 1a-hydroxylase which enables them to produce $1,25(\mathrm{OH}) 2 \mathrm{D}$ locally [15].

The effect of vitamin $D$ on the regulation of pancreatic $\beta$ cell function and insulin secretion could be mediated through intracellular changes in the calcium pool. 
Vitamin $D$ could also enhance insulin sensitivity by stimulating insulin receptor gene expression thereby enhancing insulin-mediated glucose transport [19].

Also, vitamin $D$ may be needed to ensure a normal rate of calcium flux across cell membranes and maintenance of an adequate cytosolic calcium pool, which is important for insulin-mediated intracellular signaling in insulin-responsive tissues [20].

Finally, several studies suggest that vitamin D could play a role in the pathogenesis of diabetes mellitus type 2 by affecting insulin sensitivity of $\beta$ cell function [21,22]. Vitamin $D$ is also essential for proper fetal programming and its deficiency during pregnancy may lead to low birth weight and increased susceptibility to chronic disease later in life [23]. In group $A, 8 \%$ had a history of GDM. Calcium and periconceptional multivitamin intake in both groups did not show statistical significance. Jain Madhu et al [24] also had a similar finding in their study.

In group $A 92 \%$ had low sun exposure (physical activity in the sun <3hrs) and in group B $68 \%$ had low sun exposure. This paradox of the majority of the study population having low sun exposure, in a tropical country like India despite abundant sunlight for most of the year, can be explained due to many prevalent social and cultural practices.

Overall $78 \%$ of the study population are vitamin $D$ deficient. Sahu $M$ et al. showed a prevalence of $74.1 \%$ from the north-eastern part of India [25]. Sachan $A$ et al reported a prevalence of $84.3 \%$ urban and $83.6 \%$ in a rural area [26]. The mean maternal serum vitamin $D$ levels were $9.25 \pm 6.07$ $\mathrm{ng} / \mathrm{ml}$ in Group A and $18.11 \pm 7.86 \mathrm{ng} / \mathrm{ml}$ in group B. The difference was statistically significant reflecting that the mean serum vitamin $D$ was decreased in women with GDM. Similarly, Zhang C et al [20], Muthukrishnan Jayaraman et al [27], Debnath Arijit et al [28], and PleskaIová Anna et al [29] also found a similar association between Vitamin $D$ levels and GDM.

Poel et al. in a meta-analysis of four out of seven observational studies have reported a high incidence of Vitamin D deficiency ( $>50 \%, 25(\mathrm{OH})<50$ $\mathrm{nmol} / \mathrm{L}$ ) in pregnant women with the risk of GDM with an Odds ratio of 1.61 [30]. Contrary to the present study, Farrant et al. found no association between maternal Vitamin $D$ status and risk of GDM in a cross-sectional study of 559 women from south India at the gestational age of thirty weeks.
However, he found a negative correlation between $25(\mathrm{OH}) \mathrm{D}$ and 30 minutes of the blood sugar level, after adjustment of age and BMI [31].

There is a negative correlation between the Vitamin D levels and fasting blood sugar, higher levels of fasting blood sugar were found in women with lower Vitamin $D$ levels. A negative correlation was also seen between the Vitamin D levels and HbA1c, thus indicating poor glycemic control, this inverse relation was found to be statistically significant. Similar observations were made by El Lithy et al. [32] and Debnath Arijit et al [27].

Thus, low serum Vitamin $D$ levels were associated with Gestational diabetes mellitus (GDM). So finally, it was concluded that the maternal serum Vitamin $D$ level could be done as a routine investigation in pregnancy and Vitamin $D$ deficiency should be treated to avoid the risk of GDM.

\section{Limitations}

India is a country with a high predisposition for insulin resistance leading to Vitamin D deficiency. Genetic factors in Asian women adds to it. Therefore large-randomized trials are needed to confirm our results and to find if Vitamin $D$ supplementation could improve glycemic control in women with GDM and reduce the adverse outcome in mother and fetus.

\section{Conclusion}

The present study concludes that there is a high prevalence of Vitamin $D$ deficiency in the present study population. Low serum Vitamin D levels were associated with Gestational diabetes mellitus (GDM). Maternal serum Vitamin D level can be done as a routine investigation in pregnancy and Vitamin $D$ deficiency should be treated to avoid the risk of GDM. It was also found that a negative correlation between Vitamin $D$ levels and blood sugar levels and also a negative correlation was seen between Vitamin D levels and HbA1c. Thus, low Vitamin D levels are associated with poor glycemic control.

\section{What does the study add to the existing knowledge}

To avoid complications as a result of Vitamin D deficiency in the mother and fetus, antenatal counseling regarding diet, personal habits, Vitamin D level status, regular ANC visit, and follow-up is necessary to improve the feto-maternal outcome. 


\section{Reference}

01. Metzger BE, Coustan DR, Organizing Committee. Proceedings of the Fourth International Work-shop-Conference on Gestational Diabetes Mellitus. Diabetes Care. 1998;21(2)B161-B167.

[Crossref]

02. Hirst JE, Raynes-Grenow CH, Jeffery HE. A systematic review of trends of gestational diabetes mellitus in Asia. J Diabetes Asia Study Group. 2012;3(4)1-12.

[Crossref]

03. Yang L. The relationship of serum 25-hydroxy Vitamin $D$ levels and insulin resistance in healthy women at reproductive age in Beijing. Chin Clin Obstet Gynecol. 2012;13(4)263-266. [Crossref]

04. Dror DK. Vitamin D, status during pregnancymaternal, fetal, and postnatal outcomes. Curr Opin Obstet Gynecol. 2011;23(6)422-426.

doi: $10.1097 /$ GCO.0b013e32834cb791 [Crossref]

05. Pittas AG, Lau J, Hu FB, Dawson-Hughes B. The role of vitamin $D$ and calcium in type 2 diabetes- A systematic review and metaanalysis. J Clin Endocrinol Metab. 2007;92(6)2017-2029.

doi: 10.1210/jc.2007-0298 [Crossref]

06. Ozfirat Z, Chowdhury TA. Vitamin D deficiency and type 2 diabetes. Postgrad Med J. 2010;86(1011)18-25; quiz 24.

doi: $10.1136 / p g m j .2009 .078626$ [Crossref]

07. Chu SY, Callaghan WM, Kim SY, Schmid CH, Lau J, England LJ, et al. Maternal obesity and risk of gestational diabetes mellitus. Diabetes Care. 2007;30(8)2070-2076.

doi: $10.2337 / \mathrm{dc06}-2559 \mathrm{a} \quad$ [Crossref]

08. Solomon CG, Willett WC, Carey VJ, RichEdwards J, Hunter DJ, Colditz GA, et al. A prospective study of pregravid determinants of gestational diabetes mellitus. JAMA. 1997;278(13)1078-1083.

doi: 10.1001/jama.1997.03550130052036 [Crossref]
09. Holick MF. Vitamin D deficiency. N Engl J Med. 2007;357(3)266-281.

doi: $10.1056 /$ NEJMra070553 [Crossref]

10. Parikh SJ, Edelman M, Uwaifo GI, Freedman RJ, Semega-Janneh $M$, Reynolds J, et al. The relationship between obesity and serum 1,25 dihydroxy vitamin $D$ concentrations in healthy adults. J Clin Endocrinol Metab. 2004;89(3)1196-1199.

doi: $10.1210 /$ jc. 2003-031398 [Crossref]

11. Cheng S, Massaro JM, Fox CS, Larson MG, Keyes MJ, McCabe EL, et al. Adiposity, cardiometabolic risk, and vitamin D status the Framingham Heart Study. Diabetes. 2009;59(1)242-248.

doi: $10.2337 / \mathrm{db} 09-1011$ [Crossref]

12. Mezza TL, Muscogiuri G, Sorice GP, Prioletta A, Salomone $E$, Pontecorvi A, et al. Vitamin D Deficiency- A New Risk Factor for Type 2 Di abetes?. Ann Nutri Metabol. 2012;61(4)337-48. doi: $10.1159 / 000342771$ [Crossref]

13. Burris $\mathrm{HH}$, Camargo Jr, CA. Vitamin $\mathrm{D}$ and Gestational Diabetes Mellitus. Curr Diab Rep. 2014;14(1)451.

doi: $\quad 10.1007 / \mathrm{s} 11892-013-0451-3 \quad$ [Crossref]

14. Webb AR. Who, what, where and wheninfluences on cutaneous vitamin $D$ synthesis. Prog Biophys Mol Biol. 2006;92(1)17-25.

doi: 10.1016/j.pbiomolbio.2006.02.004 [Crossref]

15. Barrett $H$, McElduff A. Vitamin D and pregnancyan old problem revisited. Best Prac Res Clin Endocrinol Metabol. 2010;24(4)527-539.

doi: $\quad 10.1016 / j$.beem.2010.05.010 [Crossref]

16. Shin JS, Choi MY, Longtine MS, Nelson DM. Vitamin $D$ effects on pregnancy and the placenta. Placenta. 2010;31(12)1027-1034.

doi: 10.1016/j.placenta.2010.08.015 [Crossref]

17. Weisman $Y$, Harell A, Edelstein $S$, David $M$, Spirer Z, Golander AL. 1 a, 25-Dihydroxyvitamin D 3, and 24, 25-dihydroxyvitamin D 3 in vitro synthesis by human decidua and placenta. Nature. 1979;281(5729)317-319.

doi: $10.1038 / 281317 a 0$ [Crossref] 
18. Evans KN, Bulmer JN, Kilby MD, Hewison M. Vitamin $D$ and placental-decidual function. J Soc Gynecol Investig. 2004;11(5)263-271.

doi: $10.1016 /$ j.jsgi.2004.02.002 [Crossref]

19. Pittas AG, Dawson-Hughes B. Vitamin D and diabetes. J Steroid Biochem Mol Biol. $2010 ; 121(1-2) 425-429$.

doi: $\quad 10.1016 /$ j.jsbmb.2010.03.042 [Crossref]

20. Zhang C, Qiu C, Hu FB, David RM, Van Dam RM, Bralley $A$, et al. Maternal plasma 25hydroxyvitamin $D$ concentrations and the risk for gestational diabetes mellitus. PloS one. 2008;3(11)e3753.

doi: $10.1371 /$ journal.pone.0003753 [Crossref]

21. Chiu KC, Chu A, Go VL, Saad MF. Hypovitaminosis $D$ is associated with insulin resistance and $\beta$ cell dysfunction. Am J Clin Nutri. 2004;79(5)820-825.

doi: $10.1093 / a j c n / 79.5 .820$ [Crossref]

22. Labriji-Mestaghanmi $H$, Billaudel B, Garnier PE, Malaisse WJ, Sutter BC. Vitamin D and pancreatic islet function I, Time course for changes in insulin secretion and content during vitamin $D$ deprivation and repletion. J Endocrinol Invest. 1988;11(8)577-584.

doi: $10.1007 /$ BF03350185 [Crossref]

23. Reichetzeder $C$, Chen $H$, Foeller $M$, Slowinski $T$, $\mathrm{Li}$ J, Chen YP, et al. Maternal vitamin D deficiency and fetal programming-lessons learned from humans and mice. Kidney Blood Pressure Res. 2014;39(4)315-329.

doi: $10.1159 / 000355809$ [Crossref]

24. Jain M, Kapry S, Jain S, Singh SK, Singh TB. Maternal Vitamin D Deficiency- A Risk Factor for Gestational Diabetes Mellitus in North India. Gynecol Obstet. 2015.

doi: $\quad 10.4172 / 2161-0932.1000264 \quad$ [Crossref]

25. Sahu M, Bhatia V, Agarwal A, Rawat V, Saxena $V$, Pandey $A$, et al. Vitamin $D$ deficiency in rural girls and pregnant women despite abundant sunshine in Northern India. Clin Endocrinol (Oxf). 2009;(5)680-684.

doi: $10.1111 /$ j.1365-2265.2008.03360.x [Crossref]
26. Sachan A, Gupta R, Das V, Agarwal A, Awasthi PK, Bhatia V. High prevalence of vitamin $D$ deficiency among pregnant women and their newborns in Northern India. Am J Clin Nutr. 2005;81(5)1060-1064.

doi: $10.1093 /$ ajcn/81.5.1060 [Crossref]

27. Muthukrishnan J, Dhruv G. Vitamin D status and gestational diabetes mellitus, Indian. J Endocrinol Metabol. 2015;19(5)616-619. doi: $10.4103 / 2230-8210.163175$ [Crossref]

28. Debnath A, Gupta M, Jain S, Kumari S, Biswas T, Ray $S$, et al. Hypovitaminosis $D$ is Associated with Gestational Diabetes Mellitus. J Clin Diag Res. 2017;11(10)QC01-QC03. [Crossref]

29. Pleskačová A, Bartáková V, Pácal L, Kuricová K, Bělobrádková J, Tomandl J, et al. Vitamin D Status in Women with Gestational Diabetes Mellitus during Pregnancy and Postpartum. BioMed Res Int. 2015;7.

doi: $10.1155 / 2015 / 260624$ [Crossref]

30. Poel YHM, Hummel P, Lips $P$, Stam F, van der Ploeg et al. Vitamin $D$ and gestational diabetesA systematic review and meta-analysis. Eur J Int Med. 2012;23(5)465-469.

doi: 10.1016/j.ejim.2012.01.007 [Crossref]

31. Farrant HJ, Krishnaveni GV, Hill JC, Boucher BJ, Fisher DJ, Noonan $\mathrm{K}$ et al. Vitamin $\mathrm{D}$ insufficiency is common in Indian mothers but is not associated with gestational diabetes or variation in newborn size. Eur J Clin Nutr. 2009;63(5)646-652.

doi: $10.1038 /$ ejen.2008.14 [Crossref]

32. El Lithy A, Abdella RM, El-Faissal YM, Sayed AM, Samie RM. The relationship between low maternal serum vitamin $D$ levels and glycemic control in gestational diabetes assessed by HbA1c levels- an observational cross-sectional study. BMC pregnancy and childbirth. $2014 ; 14(1) 362$.

doi: 10.1186/1471-2393-14-362 [Crossref] 